\title{
Doppler Blood Flow Characteristics and Hemodynamic Features in Posterior Circulation in Normal
}

\author{
A. Yu. Vishnyakova ${ }^{a}$ *, A. B. Berdalin ${ }^{a}$, S. E. Lelyuk ${ }^{b}$, and V. G. Lelyuk ${ }^{a}$ \\ ${ }^{a}$ Federal Center of Brain Research and Neurotechnolodies of the Federal Medical Biological Agency of Russia, Moscow, Russia \\ ${ }^{b}$ Russian Medical Academy of Continuous Professional Education of the Ministry of Healthcare of the Russian Federation, \\ Moscow, Russia \\ *e-mail:vishau@yandex.ru
}

Received December 25, 2020; revised April 9, 2021; accepted June 25, 2021

\begin{abstract}
The aim of this study was to determine reference doppler values of blood flow and to investigate features of normal hemodynamics in main arteries of posterior circulation using color-coded duplex sonography (DS). The study involved 65 apparently healthy male volunteers aged 21 to 57 years (36 \pm 12 years). A decrease in peak blood flow velocities during the transition from V1-segment of vertebral artery (VA) to V2 and an increase at intracranial level from proximal to distal part (from V4-segments of VA to distal part of basilar artery (BA)) were recorded. There was a tendency towards higher blood flow values in left VA and in posterior cerebral artery (PCA) in comparison with right ones. The features of hemodynamics, most likely, were due to the structural features of posterior circulation arteries-frequent asymmetry of VA in diameters, different branching of BA, as well as differences in peripheral resistance level associated with both the activity and metabolism of blood-supplied structures and the tone of resistive vascular network (less pronounced in the supratentorial structures).
\end{abstract}

Keywords: ultrasound diagnostics, posterior circulation, hemodynamic features, reference values

DOI: $10.1134 / \mathrm{S} 0362119722010157$

Ultrasound investigation of posterior circulation is included in the DS Standard Protocol and is widely used in current clinical practice. This method is used both in hospitals with specialized departments for patients with acute disorders of cerebral circulation [1], and in outpatient practice for patients with complaints of dizziness, unsteadiness when walking, coordination disorders and other symptoms which outside of acute conditions are usually regarded as chronic vertebrobasilar insufficiency [2].

However, at present time, both investigation itself and the interpretation of its results are cause difficulties due to the significant range of Doppler blood flow characteristics in the arteries of posterior circulation, even in practically healthy individuals. This circumstance, of course, is connected with the features of anatomical structure of this vascular circulation. Among them it would like to note the following: the frequently occurring diameter asymmetry of VA, the presence of VA muscular branches at the extracranial level, the fusion of both VA into BA in the area of the brain pons, the presence of three pairs of cerebellar arteries (branchers of BA) and division of BA distal part into two PCA [3, 4]. Arterial anastomoses at the level of brain stem are mainly located inside the brain tissue itself, and in the area of the occipital lobes of the large hemispheres-on the surface of the brain. Anas- tomoses of large arteries are posterior sections of the circle of Willis and the bulbar arterial ring [3, 4]. Such a unique structure of the posterior circulation requires a more detailed approach to assessing its hemodynamic features.

Currently, the results of ultrasound evaluation of hemodynamic parameters in the arteries of posterior circulation in practically healthy individuals has been published [5, 6], and their dependence on gender [7] and age $[6,8]$ has been studied. However, the addition of existing knowledge in this area with new data in connection with introduction into practice of modern ultrasound systems of expert class, as well as angiographic techniques is not only justified, but also necessary.

Thus, the aim of this study was to determine reference doppler values of blood flow and to investigate features of normal hemodynamics in main arteries of posterior circulation using color-coded DS.

\section{METHODS}

The study included data on 65 practically healthy volunteers aged 21 to 57 years ( $36 \pm 12$ years) examined on an outpatient basis. 
Table 1. The structure variants of the posterior circulation main arteries registered during duplex scanning (DS)

\begin{tabular}{l|c|c}
\hline \multicolumn{1}{c|}{ Structure variants } & $n=65$ & \% of the entire sample \\
\hline Normal structure & 51 & 78.5 \\
Hypoplasia or small diameter of the right VA & 6 & 9.3 \\
Hypoplasia or small diameter of the left VA & 3 & 4.6 \\
High entry of the right VA into the transverse processes canal & 4 & 6.2 \\
of the cervical vertebrae at the level of C5-C6 or C4-C5 & & 1.5 \\
Fetal type of PCA & 1 & \\
\hline
\end{tabular}

VA-vertebral artery, PCA-posterior cerebral artery, $n$-number of subjects.

The inclusion criteria were male gender and age from 20 to 60 years. The exclusion criteria were: female gender, presence of anemia, diabetes mellitus, acute disorders of cerebral circulation and myocardial infarction, history of heart failure of any severity and etiology, diseases of the respiratory system, respiratory insufficiency of any severity, obesity, as well as any stenosis or occlusion of posterior circulation arteries and atherosclerotic lesions in the carotid arteries (stenosis $>30 \%$, ECST). Volunteers over the age of 60 were not included in the study due to the impossibility, in the vast majority of cases, classifying them as "practically healthy" individuals.

All persons included in the study underwent highresolution color-coded DS of the extracranial parts of the carotid and vertebral arteries and transcranial color-coded DS of the cerebral arteries on Acuson Sequoia-512 and S-2000 ultrasound systems (Siemens $A G$, Germany) with electronic multi-frequency broadband linear sector phased sensors with scanning frequencies from 5 to 9 and from 2 to $4 \mathrm{MHz}$, respectively.

In DS, blood flow velocity and interintimal (intraluminal) diameters of VA V1 and V2 segments (at the level of C3-C6 vertebrae) were evaluated. In transcranial DS, the blood flow velocities in the V4 segments of VA, proximal, middle and distal third of BA (at different location depths, respectively $-70-80,80-90$ and $90-100 \mathrm{~mm}$ ), in the P1 and P2 segments of PCA were evaluated.

Statistical analysis was performed using SPSS software version 23.0 (IBM, USA) and $R$ software version 3.3.2. The null hypothesis was rejected at the significance level $p \leq 0.05$. Median and quartiles, minimum and maximum values were used to describe quantitative variables, frequency and percentage were used for qualitative variables. When analyzing correlations between quantitative or ordinal variables, the Spearman correlation coefficient calculation method was used. The analysis of the spatial dynamics of blood flow indicators was carried out using a general linear model with repeated measurements.

\section{RESULTS}

The "normal" (classical) structure of main arteries of posterior circulation according to the DS data was in $78.5 \%$ of cases in the studied men voluntaries. In the remaining $21.5 \%$, variants of the posterior circulation arteries structure were identified. The most frequent of them was hypoplasia (diameter less than $2 \mathrm{~mm}$ ) or small diameter (diameter from 2.0 to $2.5 \mathrm{~mm}$ ) of the right VA (9.3\%). Hypoplasia or small diameter of any one of the VA occurred in $13.8 \%$ of cases (Table 1).

When assessing the differences in the diameters of paired VA in studied sample of individuals, a statistically significant predominance of the left VA diameter over the right was revealed. The diameter of the left VA was more than of the right one in $64.4 \%$ of cases; the average diameter of the left VA was greater than diameter of the right VA on $0.5 \mathrm{~mm}(p=0.001)$ (Table 2). The diameter of the VA at the extracranial level (on the segment V1-V2) were not significantly changed across each of the arteries.

The results of linear blood flow velocities and peripheral vascular resistance indices measuring revealed the presence of certain flow gradients in the posterior circulation arteries on the neck and in the head (Fig. 1, Tables 3 and 4). The blood flow velocity in VA from V1 to the V2 segment significantly decreased at the extracranial level, and significantly increased on the intracranial level-from the V4 segments of the VA to distal third of BA. At the same time, the pulsatility index (PI) at V1 to the V2 segment of the VA significantly decreased, and it was significantly lower intracranially than on the neck. In the section from the V4 segments of the VA-in the BAto the P1 segments of the PCA-it did not significantly change. It was significantly smaller in the P2 segments of the PCA.

There were no data indicating the presence of asymmetry of linear blood flow velocities and peripheral resistance indices in the VA (V1- and V2-segments) and in the PCA between the right and left sides. At the same time, the estimated blood flow velocities in the left VA were slightly higher, and the level of peripheral resistance was lower than on the right VA (Fig. 1, Tables 3 and 4). Similar data were 
Table 2. The results of measuring the diameters of the vertebral artery (VA) (median (percentiles 25; 75), minimum-maximum values)

\begin{tabular}{|c|c|c|}
\hline Segment & Right VA & Left VA \\
\hline V1 segment & $\begin{array}{c}3.1 \\
(2.8 ; 3.6) \\
1.6-4.1\end{array}$ & $\begin{array}{c}3.5^{*} \\
(3.1 ; 3.9) \\
1.8-4.4\end{array}$ \\
\hline V2 segment (at the level of C4-C6 cervical vertebrae) & $\begin{array}{c}3.1 \\
(2.8 ; 3.5) \\
1.4-4.2\end{array}$ & $\begin{array}{c}3.4^{*} \\
(3.1 ; 3.7) \\
2.1-4.7\end{array}$ \\
\hline V2 segment (at the level of $\mathrm{C} 3-\mathrm{C} 4$ cervical vertebrae) & $\begin{array}{c}3.2 \\
(2.9 ; 3.6) \\
1.2-4.2\end{array}$ & $\begin{array}{c}3.6^{*} \\
(3.1 ; 3.9) \\
2.1-4.7\end{array}$ \\
\hline
\end{tabular}

V1-first segment of the VA (from the mouth to the entrance to the transverse processes canal of the cervical vertebrae); V2-second segment of the VA (in the transverse processes canal of the cervical vertebrae C6-C2); *-significant differences in the diameters of the VA between sides, $p<0.05$.

obtained for PCA-blood flow velocities in the left PCA were slightly higher than in the right. There were no significant correlations of the blood flow velocities in the ispilateral VA and PCA. At the same time, blood flow velocity in both VA (on the right side only the peak systolic blood flow velocity (Vps), on the left-all velocities) correlated with those in BA. For example, correlation coefficient between the Vps in the right VA (V2 segment at the C3-C4 level) and the Vps in the BA (middle third) turned out to be 0.34 , and for the left VA it was $0.54(p=0.001)$. In turn, the blood flow velocities in BA did not significantly correlate with those in PCA on both sides. Indices of peripheral vascular resistance in VA, BA and PCA showed significant correlations with each other and correlation coefficients was around 0.55 on average $(p=0.001)$.

With correlation analysis, it was significant positive relationship revealed between diameters of the VA and linear blood flow velocities (end-diastolic $(\mathrm{Ved})$ and time-averaged maximum $(T A M X)$ velocity) in the same arteries; an inverse relationship was between diameters of the VA and the indices of the peripheral
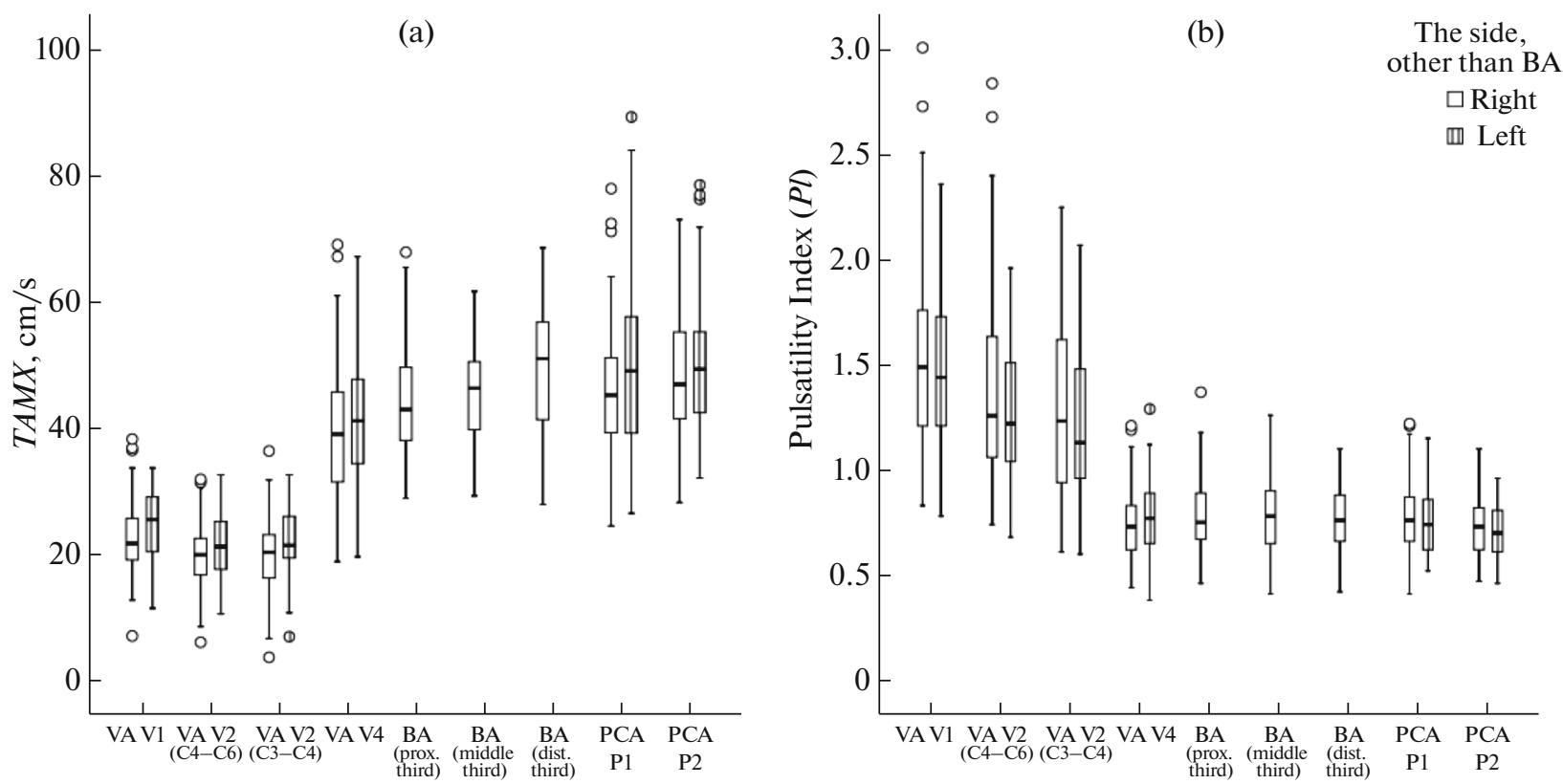

Fig. 1. The time-averaged maximum blood flow velocity $(T A M X)$ and pulsatility index $(P I)$ in the arteries of the posterior circulation. (a) The time-averaged maximum blood flow velocity in different arteries of posterior circulation, (b) the pulsatility index in different arteries of the posterior circulation; graphical representation (boxplots). VA-vertebral artery, V2, V4-VA segments, C4-C6, C3-C4-cervical vertebrae (VA assessment level), BA-basilar artery (proximal, middle and distal third), PCA-posterior cerebral artery, $\mathrm{P} 1, \mathrm{P} 2-\mathrm{PCA}$ segments. 
Table 3. Doppler blood flow velocities and peripheral resistance indices in extracranial vertebral arteries (VA) (median (percentiles 25; 75), minimum-maximum values)

\begin{tabular}{l|c|c|c|c|c|c}
\hline \multicolumn{1}{c|}{ VA } & $V p s, \mathrm{~cm} / \mathrm{s}$ & $V e d, \mathrm{~cm} / \mathrm{s}$ & $T A M X, \mathrm{~cm} / \mathrm{s}$ & $T A V, \mathrm{~cm} / \mathrm{s}$ & $P I$ & $R I$ \\
\hline \multirow{4}{*}{ V1 on the right side } & 45.5 & 13.4 & 21.6 & 11.7 & 1.49 & 0.71 \\
& $(38.6 ; 53.9)$ & $(11.4 ; 16.0)$ & $(18.9 ; 25.8)$ & $(9.9 ; 14.0)$ & $(1.21 ; 1.77)$ & $(0.66 ; 0.76)$ \\
& $19.6-85.7$ & $3.6-25.8$ & $6.9-38.2$ & $2.8-19.6$ & $0.83-3.01$ & $0.54-0.87$ \\
\hline \multirow{4}{*}{ V2 (C 4-C6) on the right side } & $37.8^{*}$ & $12.5^{*}$ & $19.8^{*}$ & $11.2^{*}$ & $1.26^{*}$ & $0.66^{*}$ \\
& $(33.6 ; 45.8)$ & $(10.6 ; 14.7)$ & $(16.6 ; 22.5)$ & $(9.9 ; 13.0)$ & $(1.06 ; 1.64)$ & $(0.62 ; 0.74)$ \\
& $17.0-67.2$ & $2.8-22.7$ & $5.9-31.8$ & $7.2-22.3$ & $0.74-2.84$ & $0.53-0.84$ \\
\hline \multirow{4}{*}{ V2 (C3-C4) on the right side } & $35.7^{*}$ & $13.2^{*}$ & $20.2^{*}$ & $11.4^{*}$ & $1.23^{*}$ & $0.65^{*}$ \\
& $(30.9 ; 42.4)$ & $(10.2 ; 14.7)$ & $(16.1 ; 23.0)$ & $(9.3 ; 13.6)$ & $(0.94 ; 1.62)$ & $(0.58 ; 0.73)$ \\
& $12.3-61.6$ & $0.8-25.0$ & $3.5-36.3$ & $4.9-26.0$ & $0.61-3.27$ & $0.45-0.94$ \\
\hline \multirow{5}{*}{ V1 on the left side } & 49.8 & 15.5 & 25.4 & 13.8 & 1.44 & 0.69 \\
& $(41.8 ; 57.8)$ & $(12.0 ; 18.5)$ & $(20.3 ; 29.1)$ & $(10.6 ; 15.4)$ & $(1.21 ; 1.74)$ & $(0.65 ; 0.75)$ \\
& $26.7-80.5$ & $6.0-22.6$ & $11.3-33.6$ & $5.6-20.1$ & $0.78-4.48$ & $0.57-0.92$ \\
\hline \multirow{3}{*}{ V2 on the left side } & $40.2^{*}$ & $13.5^{*}$ & $21.1^{*}$ & $11.6^{*}$ & $1.22^{*}$ & $0.66^{*}$ \\
& $(32.5 ; 46.8)$ & $(11.5 ; 16.9)$ & $(17.5 ; 25.2)$ & $(9.4 ; 14.0)$ & $(1.04 ; 1.52)$ & $(0.60 ; 0.70)$ \\
& $22.3-65.6$ & $5.1-24.3$ & $10.4-32.5$ & $4.0-18.9$ & $0.68-3.54$ & $0.53-0.89$ \\
\hline \multirow{3}{*}{ V2 (C3-C4) on the left side } & $40.1^{*}$ & $13.9^{*}$ & $21.3^{*}$ & $12.6^{*}$ & $1.13^{*}$ & $0.64^{*}$ \\
& $(35.2 ; 45.7)$ & $(12.1 ; 17.0)$ & $(19.3 ; 25.9)$ & $(10.4 ; 15.2)$ & $(0.96 ; 1.48)$ & $(0.58 ; 0.70)$ \\
& $14.0-62.2$ & $3.7-21.5$ & $6.8-32.5$ & $2.8-22.5$ & $0.60-3.53$ & $0.47-0.88$ \\
\hline
\end{tabular}

$V p s$-peak systolic blood flow velocity, $\mathrm{cm} / \mathrm{sec}, \mathrm{Ved}$-end-diastolic blood flow velocity, $\mathrm{cm} / \mathrm{s}, T A M X$-time-averaged maximum blood flow velocity, cm/s, TAV - time-averaged blood flow velocity, cm/s, PI-pulsatility index (Gosling), RI-resistance index (Pourcelot); *-significant differences between the evaluated parameters in V1 and V2 segments of VA $(p<0.01)$. The rest of the notation, see Table 2.

vascular resistance level (pulsatility $(P I)$ and resistive $(R I)$ indices). So, the correlation coefficients for the right VA (C3-C4) were: diameter of the artery with Ved $r=0.53$, with TAMX $r=0.51$, with $P I r=-0.54$, with $R I r=-0.52$; for the left VA $(\mathrm{C} 3-\mathrm{C} 4)$ - the diameter of the artery with Ved $r=0.40$, with TAMX $r=$ 0.38 , with $P I r=-0.36$, with $R I r=-0.28$. The dependence of the time-averaged maximum blood flow velocity $(T A M X)$ and pulsatility index $(P I)$ on the diameter of the VA is shown in Fig. 2.

\section{DISCUSSION}

The differences in VA diameters, including significant ones, are widespread in the population and are recognized as variant of the norm. The most often dominant in terms of lumen diameter is the left VA [9, 10]. In present study, the diameter of the left VA also turned out to be larger than the right one. Such differences can be explained by the peculiarities of the VA departure: the right VA is the third division of the arteries (due to the presence of the brachiocephalic trunk), the left one is the second division (the left subclavian artery departs directly from the aortic arch). In rare cases, the left VA can independently move away from the aortic arch [11], and in this case, this will be the first division. The departure of the right VA from the aortic arch is considered an extremely rare variant, usually detected by angiography [12].

The VA diameters turn out to be genetically determined to certain extent, as indicated by A.D. Tarnoki et al., examined 172 twins (54 monozygotic and 32 dizygotic) [13]. Although it is possible that the diameters of the VA also depend on the characteristics of the embryogenesis process.

Despite the fact that significant differences in VA diameters were revealed in this study and their relationship with Doppler blood flow characteristics was shown, no significant differences in blood flow velocities and peripheral resistance indices in the right and left VA were revealed. On the left side, blood flow velocities were unreliably higher, and the peripheral resistance level was lower than on the right, which is also consistent with the literature data [6, 8]. Apparently, such differences in peripheral resistance levels can be explained by the fact that, given an approximately equal number of muscle branches in both VA, the proportion of blood flow for blood supply to brain structures in the left VA turns out to be greater than in the right, and cerebral blood flow is characterized, as is known, by low peripheral resistance. At the same time, according to the published I.W. Liu et al., it was 
Table 4. Doppler blood flow velocities and peripheral resistance indices in the intracranial parts of the vertebral (VA), basilar (BA) and posterior cerebral (PCA) arteries (median (percentiles $25 ; 75)$, minimum $-\mathrm{j}=$ maximum values)

\begin{tabular}{|c|c|c|c|c|c|c|}
\hline Artery & $V p s, \mathrm{~cm} / \mathrm{s}$ & $\operatorname{Ved}, \mathrm{cm} / \mathrm{s}$ & $T A M X, \mathrm{~cm} / \mathrm{s}$ & $T A V, \mathrm{~cm} / \mathrm{s}$ & $P I$ & $R I$ \\
\hline $\begin{array}{l}\text { VA V4 } \\
\text { on the right side }\end{array}$ & $\begin{array}{c}56.8 \\
(44.6 ; 67.2) \\
25.2-89.3\end{array}$ & $\begin{array}{c}28.0 \\
(23.0 ; 32.9) \\
13.0-48.0\end{array}$ & $\begin{array}{c}39.0 \\
(31.3 ; 46.1) \\
18.7-69.1\end{array}$ & $\begin{array}{c}22.6 \\
(19.7 ; 29.2) \\
10.8-39.9\end{array}$ & $\begin{array}{c}0.75 \\
(0.62 ; 0.84) \\
0.44-1.21\end{array}$ & $\begin{array}{c}0.50 \\
(0.46 ; 0.55) \\
0.38-0.64\end{array}$ \\
\hline $\begin{array}{l}\text { VA V4 } \\
\text { on the left side }\end{array}$ & $\begin{array}{c}58.9 \\
(48.8 ; 74.6) \\
22.9-120.0\end{array}$ & $\begin{array}{c}29.0 \\
(24.3 ; 34.4) \\
12.7-68.0\end{array}$ & $\begin{array}{c}41.1 \\
(33.5 ; 48.1) \\
19.5-90.0\end{array}$ & $\begin{array}{c}25.0 \\
(18.8 ; 31.2) \\
10.6-49.0\end{array}$ & $\begin{array}{c}0.77 \\
(0.65 ; 0.90) \\
0.38-1.29\end{array}$ & $\begin{array}{c}0.51 \\
(0.47 ; 0.55) \\
0.34-0.65\end{array}$ \\
\hline $\begin{array}{l}\text { BA } \\
\text { (proximal third) }\end{array}$ & $\begin{array}{c}65.4^{*} \\
(55.1 ; 77.0) \\
43.4-106.7\end{array}$ & $\begin{array}{c}30.4^{*} \\
(27.0 ; 35.3) \\
20.2-49.0\end{array}$ & $\begin{array}{c}42.9^{*} \\
(37.4 ; 50.3) \\
28.8-67.9\end{array}$ & $\begin{array}{c}26.5^{*} \\
(22.4 ; 33.4) \\
11.9-42.6\end{array}$ & $\begin{array}{c}0.75 \\
(0.67 ; 0.90) \\
0.46-1.37\end{array}$ & $\begin{array}{c}0.51 \\
(0.48 ; 0.56) \\
0.38-0.68\end{array}$ \\
\hline $\begin{array}{l}\text { BA } \\
\text { (middle third) }\end{array}$ & $\begin{array}{c}67.4^{* *} \\
(56.1 ; 77.7) \\
46.4-109.7\end{array}$ & $\begin{array}{c}32.0 * * \\
(28.2 ; 37.0) \\
21.1-45.9\end{array}$ & $\begin{array}{c}46.3^{* *} \\
(39.7 ; 50.7) \\
29.2-61.7\end{array}$ & $\begin{array}{c}30.6^{* *} \\
(24.5 ; 34.9) \\
17.9-47.9\end{array}$ & $\begin{array}{c}0.78 \\
(0.65 ; 0.90) \\
0.41-1.26\end{array}$ & $\begin{array}{c}0.53 \\
(0.47 ; 0.56) \\
0.35-0.67\end{array}$ \\
\hline $\begin{array}{l}\text { BA } \\
\text { (distal third) }\end{array}$ & $\begin{array}{c}77.0^{* *, \#} \\
(61.1 ; 85.6) \\
42.0-98.8\end{array}$ & $\begin{array}{c}36.0^{* *, \#} \\
(30.1 ; 41.3) \\
18.9-50.6\end{array}$ & $\begin{array}{c}51.0^{* *, \#} \\
(41.3 ; 57.0) \\
27.8-68.6\end{array}$ & $\begin{array}{c}33.7 * *, \# \\
(28.0 ; 39.9) \\
14.7-45.4\end{array}$ & $\begin{array}{c}0.76 \\
(0.66 ; 0.88) \\
0.42-1.10\end{array}$ & $\begin{array}{c}0.52 \\
(0.47 ; 0.56) \\
0.36-0.63\end{array}$ \\
\hline $\begin{array}{l}\text { PCA P1 } \\
\text { on the right side }\end{array}$ & $\begin{array}{c}66.7^{* *} \\
(57.3 ; 78.5) \\
33.6-111.8\end{array}$ & $\begin{array}{c}31.8 * * \\
(7.6 ; 36.7) \\
17.0-59.0\end{array}$ & $\begin{array}{c}45.2 * * \\
(39.1 ; 51.1) \\
24.4-78.0\end{array}$ & $\begin{array}{c}28.6^{* *} \\
(25.1 ; 32.9) \\
15.2-42.5\end{array}$ & $\begin{array}{c}0.76 \\
(0.66 ; 0.87) \\
0.41-1.22\end{array}$ & $\begin{array}{c}0.51 \\
(0.47 ; 0.57) \\
0.35-0.67\end{array}$ \\
\hline $\begin{array}{l}\text { PCA P1 } \\
\text { on the left side }\end{array}$ & $\begin{array}{c}67.5^{* *} \\
(58.5 ; 86.8) \\
33.7-123.5\end{array}$ & $\begin{array}{c}34.8^{* *} \\
(27.5 ; 40.3) \\
17.1-67.8\end{array}$ & $\begin{array}{c}49.1 * *, \# \\
(38.8 ; 57.9) \\
26.4-89.4\end{array}$ & $\begin{array}{c}30.0 * * \\
(24.9 ; 36.3) \\
16.2-50.1\end{array}$ & $\begin{array}{c}0.74 \\
(0.62 ; 0.86) \\
0.52-1.15\end{array}$ & $\begin{array}{c}0.51 \\
(0.46 ; 0.56) \\
0.41-0.65\end{array}$ \\
\hline $\begin{array}{l}\text { PCA R2 } \\
\text { on the right side }\end{array}$ & $\begin{array}{c}70.0 * * \\
(58.2 ; 77.7) \\
38.9-100.3\end{array}$ & $\begin{array}{c}32.7^{* *} \\
(27.7 ; 39.0) \\
19.0-54.7\end{array}$ & $\begin{array}{c}46.9^{* *, \#} \\
(41.2 ; 55.3) \\
28.1-73.1\end{array}$ & $\begin{array}{c}29.7 * * \\
(26.2 ; 33.7) \\
18.8-41.5\end{array}$ & $\begin{array}{c}0.72 * *, \# \# \\
(0.62 ; 0.83) \\
0.47-1.10\end{array}$ & $\begin{array}{c}0.51 \\
(0.46 ; 0.55) \\
0.39-0.63\end{array}$ \\
\hline $\begin{array}{l}\text { PCA R2 } \\
\text { on the left side }\end{array}$ & $\begin{array}{c}69.0 * * \\
(61.9 ; 79.1) \\
47.5-109.9\end{array}$ & $\begin{array}{c}35.6^{* *} \\
(30.7 ; 39.7) \\
22.6-55.8\end{array}$ & $\begin{array}{c}49.3^{* *, \#} \\
(42.0 ; 55.4) \\
32.0-78.6\end{array}$ & $\begin{array}{c}30.8^{* *} \\
(25.2 ; 35.2) \\
18.5-49.9\end{array}$ & $\begin{array}{c}0.70 * *, \# \# \\
(0.61 ; 0.84) \\
0.46-0.96\end{array}$ & $\begin{array}{c}0.50 \\
(0.45 ; 0.54) \\
0.38-0.59\end{array}$ \\
\hline
\end{tabular}

V4-fourth segment of VA (intracranial part of the VA from entering the cavity of the skull to merge into BA), P1, P2-the first and second segments of PCA; *-significant difference with those in the right VA, $p<0.05$; **-significant differences with the respective performance in both VA, $p<0.05$; ${ }^{\#}$-significant differences with those in the proximal and middle thirds of E. BA, $p<0.05$; ${ }^{\#}-$ significant difference with those in all departments of BA and the P1 segment of PCA, $p<0.05$. The rest of the notation, see Table 3.

stated that not only hypoplasized VA, as it was previously thought, but also arteries with a diameter of up to $3.0 \mathrm{~mm}$, in particular, may end with the posterior inferior cerebellar artery and not participate in the blood supply of the BA and PCA territories [14].

This causes differences in the volume of blood supply to brain structures and affects on Doppler characteristics of intraluminal flows. The present study did not provide for simultaneous assessment of VA using tomographic angiographic methods, in particular magnetic resonance and $\mathrm{X}$-ray multispiral computed angiography - and dividing of VAs depending on their structural variants. In turn, the absence of significant differences in blood flow velocities in the group as a whole may be due to the fact that in most cases VA merge into BA and have territories similar in size and "type" of the arteriolar network.

Despite the fact that diameter of each VA remained unchanged throughout the extracranial section available for study using DS, the Doppler blood flow characteristics in the V1 and V2 segments of the VA significantly differed from each other. To a certain extent, the hemodynamics in the V1 segment of the VA and its differences from that in the V2 segment could be influenced by the nature of the flow and the pressure level in the subclavian artery, as well as the features of the departure VA (the angle of departure, the absence deformation above the mouth of the VA) from the sub- 

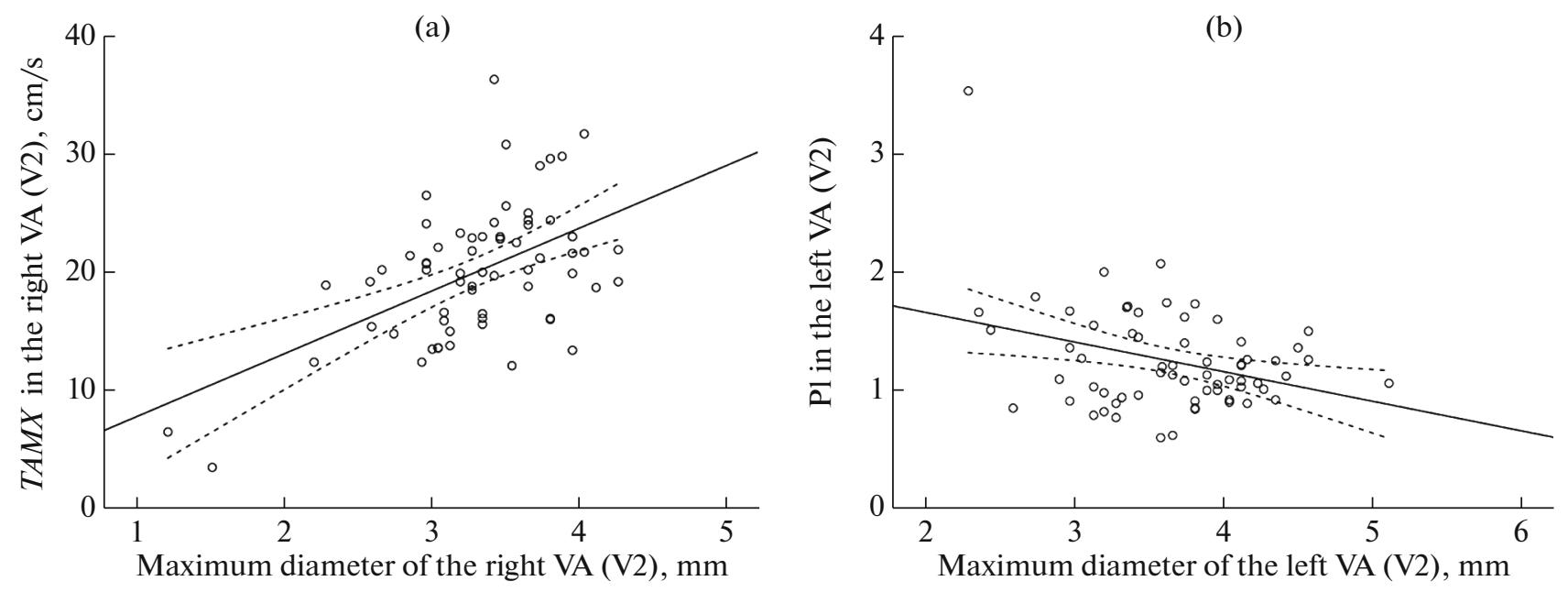

Fig. 2. The dependence of TAMX in (a) the right VAand PI in the left VAon the diameters of the arteries. a-the dependence of the time-averaged maximum blood flow velocity in the right VA on its diameter, $b$ - the dependence of the pulsatility index in the left VA on its diameter. For the rest of the designations, see Fig. 1.

clavian artery. It is also possible that differences in VA branching in V1 and V2 segments played a more significant role. In addition to muscle branches (rami musculares), departing from VA in both V1- and V2segments and supplying blood to the prevertebral muscles, a number of other larger ones depart from the V2segments of the VA. These include the radicular arteries (paired segmental branches to the spine, dura mater spinalis and cervical roots) and 3-5 unpaired radicular-spinal arteries forming a vessel in the anterior median furrow of the spinal cord, which is spinal extension of the anterior spinal artery and plays an important role in blood supply to the spinal cord [3].

The main structure feature of the posterior circulation, as already noted above, is the merging of two large VA into one BA trunk. This circumstance also causes certain changes in hemodynamics in this area. Linear blood flow velocities in intracranial segments of the VA did not differ significantly from each other, but at the same time, the blood flow velocities in the right VA were statistically significantly lower than in the proximal BA. On the left side, on the contrary, the blood flow velocity in the VA does not significantly differ from that in the proximal part of BA, which was probably due to the fact that the BA can be considered as a continuation of the larger diameter VA, which, as shown earlier, is the left VA. At the same time, the blood flow velocities in the BA significantly correlated with those in both VA, the correlation coefficient for the left VA was higher than for the right. Indeed, according to pathologic-anatomical and angiographic studies, BA is usually indirect, has $C$ - or $S$-shaped course, since it is continuation of larger diameter artery; the knee of deformation is located on the side of smaller diameter VA, which under similar circumstances flows into the dominant VA at an angle close to a straight one $[4,10]$.
For the first time, the differences in the blood flow velocities in different (conditionally isolated) parts of the BA may be consequence of the peculiarities of large number of different diameters branches departure from it and the discharge of blood into their lumen. Most likely, we are talking about the departure of significant number of relatively large branches in the distal part of the BA (posterior cerebral and upper cerebellar arteries) in comparison with its other departments [3, 4]. These vessels have an extensive network of arterioles in the occipital lobes and cerebellum, which creates a certain pressure gradient in the BA. At the same time, the diameter of the BA decreases from the proximal to the distal part due to branching although insignificant. There are no indications of this in previously published angiographic and pathoanatomic studies, this issue requires further clarification.

It should be noted that blood flow in the PCA did not correlate with that in either ipsilateral VA or BA. Perhaps it should be determined by the nature of the division and the diameters of the PCA themselves [10]. In some cases, the blood flow in the PCA may depend on the blood flow in the anterior circulation, especially in cases of fetal structure of the PCA [3].

Feature of blood flow values in PCA is the absence of significant decrease in the blood flow velocity from $\mathrm{P} 1$ segments to $\mathrm{P} 2$, and even some increase in it. This is radically different from the picture observed in the anterior circulation, where blood flow velocity in the middle cerebral artery, on the contrary, decreases from the proximal to distal part (from M1 to M2 and M3 segments). Probably, this may be due to the absence of large branches of the PCA in the P1 segment due to its short duration, as well as, possibly, some decrease in the diameter of the PCA in the distal direction and the 
influence of blood flow from the anterior circulation along posterior connective arteries.

The obtained data is illustrated that indices of peripheral resistance in the P2 segments of the PCA turned out to be the smallest of those estimated in the intracranial arteries of posterior circulation (in the P1 segments of the PCA and BA). Presumably them may indicate that proportion of blood volume for the cortical structures blood suppling increases from the V4 segment of the VA to the P2 segments of the PCA. As noted earlier, a characteristic feature of posterior circulation is that it supplies phylogenetically and anatomically heterogeneous structures with different angioarchitectonics and different levels of tissue metabolism (on the one hand, these are the structures of the brain stem and cerebellum, on the other-the occipital lobes of the large hemispheres) [4]. Therefore, it can be reasonably assumed that at different levels of the posterior circulation, the tone of the resistive vascular network turns out to be different-in the cortical sections it is lower. This may also cause the presence of a pressure gradient from the proximal parts of the posterior circulation (V4 segments of the VA) to the distal (distal part of BA and PCA).

Thus, the Doppler blood flow characteristics in the arteries of posterior circulation were evaluated at the extra- and intracranial levels in this study. The revealed differences in Doppler blood flow characteristics in different arteries of posterior circulation do not contradict the currently formed ideas about the features of hemodynamics in this vascular territory, and also supplement them with new data.

\section{CONCLUSIONS}

(1) The diameter of the left VA was often lager than the diameter of the right VA (about $65 \%$ of cases), which caused a tendency to a higher blood flow velocity with less peripheral resistance in the left VA than in the right.

(2) Significant positive correlations were revealed between the VA diameters, on the one hand, and linear blood flow velocity (end-diastolic and time-averaged maximum velocities) in them, on the other; inverse correlations were found between VA diameters and indices of the peripheral vascular resistance level (pulsatility and resistive indices).

(3) At the extracranial level, there was decrease in linear blood flow velocities along the VA from V1-segment to V2, whereas at the intracranial level, the opposite pattern was recorded-an increase in linear blood flow velocities from the proximal parts (V4-segments of the VA) to the distal (distal third of the BA).

(4) It is established that, it is possible to register an increase in the intraluminal linear blood flow velocities into the BA from its proximal to distal parts in normal by using ultrasound DS, which should be taken into account when conducting "reference" comparisons.

(5) Indices of peripheral resistance level in the intracranial arteries of the posterior circulation showed a decrease from the proximal areas (VA) to the distal (P2 PCA), which most likely reflected similar changes in the tone of the distal vascular network.

\section{FUNDING}

The work was carried out within the framework of the State Task no. 056-00171-19-01. The registration number AAAAA-A19-119042590018-0 (dated March 29, 2019).

\section{ETHICAL STANDARDS}

All studies were conducted in accordance with the principles of biomedical ethics formulated in the Helsinki Declaration of 1964 and its subsequent updates, and approved by the local Bioethical Committee of the Federal Center of brain research and neurotechnologies of the FMBA (Moscow).

\section{INFORMED CONSENT}

Each participant of the study submitted a voluntary written informed consent signed by him after explaining to him the potential risks and benefits, as well as the nature of the upcoming study.

\section{CONFLICT OF INTEREST}

The authors declare the absence of obvious and potential conflicts of interest associated with the publication of this article.

\section{OPEN ACCESS}

This article is licensed under a Creative Commons Attribution 4.0 International License, which permits use, sharing, adaptation, distribution and reproduction in any medium or format, as long as you give appropriate credit to the original author(s) and the source, provide a link to the Creative Commons license, and indicate if changes were made. The images or other third party material in this article are included in the article's Creative Commons license, unless indicated otherwise in a credit line to the material. If material is not included in the article's Creative Commons license and your intended use is not permitted by statutory regulation or exceeds the permitted use, you will need to obtain permission directly from the copyright holder. To view a copy of this license, visit http://creativecommons.org/licenses/by/4.0/.

\section{REFERENCES}

1. Prikaz Ministerstva zdravookhraneniya RF no. 928 ot 15 noyabrya $2012 \mathrm{~g}$. Ob utverzhdenii poryadka okazaniya meditsinskoi pomoshchi bol'nym s ostrymi narusheniyami mozgovogo krovoobrashcheniya (s izmeneniyami na 21 fevralya 2020 g.) (Order of the Ministry of Health of Rus- 
sian Federation No. 928n of November 15, 2012 On Approval of the Procedure for the Provision of Medical Care to Patients with Acute Cerebrovascular Injuries (with Amendments on February 21, 2020)), Moscow, 2020.

2. Neto, A.C.L., Bor-Seng-Shu, E., Oliveira, M.L., et al., Magnetic resonance angiography and transcranial Doppler ultrasound findings in patients with a clinical diagnosis of vertebrobasilar insufficiency, Clinics (Sao Paulo), 2020, vol. 20, no. 75, p. e1212.

3. Haines, D.E., Neuroanatomy: An Atlas of Structures, Sections, and Systems, Baltimore, PA: Lippincott Williams \& Wilkins, 2004.

4. Valdueza Barrios, J.M., Schreiber, S., Röhl, J.-E., Connolly, F., and Klingebiel, R., Neurosonology and Neuroimaging of Stroke: A Comprehensive Reference, New York, NY: Thieme, 2008.

5. Albayrak, R., Degirmenci, B., Acar, M., et al., Doppler sonography evaluation of flow velocity and volume of the extracranial internal carotid and vertebral arteries in healthy adults, J. Clin. Ultrasound., 2007, vol. 35, no. 1, p. 27.

6. Lelyuk, V.G. and Lelyuk, S.E., Ul'trazvukovaya angiologiya (Ultrasound Angiology), Moscow: Real Taim, 2007, 3rd ed.

7. Morović, S., Škarić-Jurić, T., and Demarin, V., Morphologic and hemodynamic characteristics of vertebral arteries in men and women, Rad Med. Znatosti, 2007, vol. 31, p. 121.

8. Nemati, M., Bavil, A.S., and Taheri, N., Comparison of normal values of Duplex indices of vertebral arteries in young and elderly adults, Cardiovasc. Ultrasound., 2009, vol. 7, p. 2.

9. Hong, J.M., Chung, C.S., Bang, O.Y., et al., Vertebral artery dominance contributes to basilar artery curvature and peri-vertebrobasilar junctional infarcts, J. Neurol. Neurosurg. Psychiatry, 2009, vol. 80, no. 10, p. 1087.

10. Vitosevic, F., Rasulic, L., and Medenica, S.M., Morphological characteristics of the posterior cerebral circulation: an analysis based on non-invasive imaging, Turk. Neurosurg., 2019, vol. 29, no. 5, p. 625.

11. Einstein, E.H., Song, L.H., Villela, N.L., et al., Anomalous origin of the left vertebral artery from the aortic arch, Aorta (Stamford), 2016, vol. 4, no. 2, p. 64.

12. Goldbach, A., Dass, C., and Surapaneni, K., Aberrant right vertebral artery with a diverticulum of kommerell: review of a rare aortic arch anomaly, J. Radiol. Case Rep., 2018, vol. 12, no. 5, p. 19.

13. Tarnoki, A.D., Fejer, B., Tarnoki, D.L., et al., Vertebral artery diameter and flow: nature or nurture, $J$. Neuroimaging, 2017, vol. 27, no. 5, p. 499.

14. Liu, I.W., Ho, B.L., Chen, C.F., et al., Vertebral artery terminating in posterior inferior cerebellar artery: a normal variation with clinical significance, PLoS One, 2017, vol. 12, no. 4, p. e0175264. 